Review Article

\title{
Predictors and Modulators of Synthetic Lethality: An Update on PARP Inhibitors and Personalized Medicine
}

\author{
Stephen Murata, ${ }^{1}$ Catherine Zhang, ${ }^{1}$ Nathan Finch,, ${ }^{1}$ Kevin Zhang, ${ }^{2}$ \\ Loredana Campo, ${ }^{1}$ and Eun-Kyoung Breuer ${ }^{1}$ \\ ${ }^{1}$ Department of Radiation Oncology, Stritch School of Medicine, Loyola University Chicago, Maywood, IL 60153, USA \\ ${ }^{2}$ Department of Otorhinolaryngology, University of Pennsylvania School of Medicine, Philadelphia, PA 19104, USA
}

Correspondence should be addressed to Eun-Kyoung Breuer; eubreuer@luc.edu

Received 9 June 2016; Accepted 28 July 2016

Academic Editor: David C. Pauza

Copyright (C) 2016 Stephen Murata et al. This is an open access article distributed under the Creative Commons Attribution License, which permits unrestricted use, distribution, and reproduction in any medium, provided the original work is properly cited.

Poly(ADP-ribose) polymerase (PARP) inhibitors have proven to be successful agents in inducing synthetic lethality in several malignancies. Several PARP inhibitors have reached clinical trial testing for treatment in different cancers, and, recently, Olaparib (AZD2281) has gained both United States Food and Drug Administration (USFDA) and the European Commission (EC) approval for use in BRCA-mutated advanced ovarian cancer treatment. The need to identify biomarkers, their interactions in DNA damage repair pathways, and their potential utility in identifying patients who are candidates for PARP inhibitor treatment is well recognized. In this review, we detail many of the biomarkers that have been investigated for their ability to predict both PARP inhibitor sensitivity and resistance in preclinical studies as well as the results of several clinical trials that have tested the safety and efficacy of different PARP inhibitor agents in BRCA and non-BRCA-mutated cancers.

\section{Introduction}

DNA damage can be acquired through endogenous and exogenous sources that, if left unrepaired, can contribute to genomic instability and oncogenesis. Indeed, defects in the DDR signaling pathway are often found in various human cancers $[1-3]$. The concept of "synthetic lethality" between two genes becomes relevant when a mutation to either separately is still compatible with viability, but mutations to both genes lead to death [4]. If an oncogenetic gene mutation is viewed as the first "hit," targeting a partner gene or gene product should theoretically induce synthetic lethality in neoplastic cells. This therapy would also have minimal side effects on healthy cells with normal gene function [5]. A relevant example of synthetic lethality quickly moving to clinical application is the use of poly(ADP-ribose) polymerase (PARP) inhibitors for the treatment of $B R C A$ associated cancers. BRCA1 and BRCA2 are tumor suppressor genes encoding proteins that play important roles for DNA double-stranded break (DSB) detection for the homologous recombination (HR) repair pathway [6, 7]. Deficiencies in $B R C A 1 / 2$ function are associated with compromised HR repair, genomic instability, and oncogenesis [8-10]. PARP is a nuclear protein in the base excision repair (BER) pathway that recruits BER machinery to DNA single-stranded break (SSB) sites [5]. Inhibition of PARP would cause a collapse in the BER pathway and result in the accumulation of SSBs that break down to DSBs upon undergoing DNA replication [11-13]. In healthy cells, PARP inhibition would be of no large consequence because of effective DSB repair. However, in the context of $B R C A$-mutated cancers with compromised HR repair, breakdown of the BER pathway brought on by PARP inhibition would kill tumor cells from the buildup of DSBs [13-15]. The efforts to take advantage of synthetic lethality with PARP inhibitors have led to drug development for the treatment of patients with germline mutations in $B R C A 1 / 2$. Olaparib is a PARP1/2 inhibitor that has gained approval by both the FDA and EC for use in patients with $B R C A$-mutated advanced, recurrent, platinum-sensitive serous ovarian cancer [16]. Meanwhile, Veliparib, Niraparib, 
TABLE 1: PARP inhibitors currently undergoing development.

\begin{tabular}{|c|c|c|c|c|}
\hline PARP inhibitors & Tumor types & $\begin{array}{l}\text { Most advanced } \\
\text { developmental stage } \\
\text { in progress }\end{array}$ & Key clinical trials & References \\
\hline Olaparib & $\begin{array}{l}\text { FDA approved for ovarian cancer } \\
\text { Being tested for breast, prostate, } \\
\text { and pancreatic cancers }\end{array}$ & FDA approved & $\begin{array}{l}\text { Phase II trial found that Olaparib } \\
\text { monotherapy in patients with BRCA1/2 } \\
\text { mutated ovarian cancer following } \geq 3 \\
\text { chemotherapy treatments resulted in } 31 \% \\
\text { response rate } \\
\text { Phase II trial found that Olaparib } \\
\text { maintenance therapy in patients with } \\
\text { platinum- (Pt-) sensitive recurrent serous } \\
\text { ovarian cancer with mutated BRCA1/2 } \\
\text { resulted in median progression free } \\
\text { survival of } 6.9 \text { months longer than those } \\
\text { receiving placebo }\end{array}$ & {$[150,151]$} \\
\hline Talazoparib & $\begin{array}{l}\text { Being tested for ovarian, breast, } \\
\text { and various advanced/metastatic } \\
\text { solid cancers (primary peritoneal } \\
\text { carcinoma, fallopian tube } \\
\text { carcinoma, etc.) }\end{array}$ & Phase III & $\begin{array}{l}\text { Phase II trial for Talazoparib } \\
\text { monotherapy in patients with deleterious } \\
\text { BRCA1/2 mutated ovarian cancer who } \\
\text { had prior PARP inhibitor treatment } \\
\text { currently recruiting } \\
\text { Phase III trial for Talazoparib } \\
\text { monotherapy in patients with BRCA1/2 } \\
\text { mutated, advanced, or metastatic breast } \\
\text { cancer currently recruiting }\end{array}$ & {$[152,153]$} \\
\hline Veliparib & $\begin{array}{l}\text { Being tested for breast, } \\
\text { pancreatic, non-small-cell lung } \\
\text { cancers, lymphoma, and multiple } \\
\text { myeloma, mostly in combination } \\
\text { with chemotherapy }\end{array}$ & Phase III & $\begin{array}{l}\text { Phase I/II trial of Veliparib and Topotecan } \\
\text { for relapsed ovarian cancer of negative or } \\
\text { unknown BRCA status completed } \\
\text { Phase II trial of Veliparib alone or with } \\
\text { Gemcitabine and Cisplatin in patients } \\
\text { with locally advanced or metastatic } \\
\text { pancreatic cancer currently recruiting } \\
\text { Phase I/II trial for Veliparib, } \\
\text { Bendamustine HCl, and Rituximab in } \\
\text { patients with relapsed lymphoma and } \\
\text { multiple myeloma completed }\end{array}$ & {$[154-156]$} \\
\hline Rucaparib & $\begin{array}{l}\text { Being tested for ovarian and } \\
\text { pancreatic cancers }\end{array}$ & Phase III & $\begin{array}{l}\text { Phase III trial for Rucaparib maintenance } \\
\text { therapy in patients with Pt-sensitive } \\
\text { recurrent ovarian cancer, fallopian tube, } \\
\text { or primary peritoneal cancers currently } \\
\text { recruiting } \\
\text { Phase II trial for Rucaparib monotherapy } \\
\text { in patients with BRCA1/2 mutated, locally } \\
\text { advanced, or metastatic pancreatic cancer } \\
\text { currently ongoing }\end{array}$ & {$[157,158]$} \\
\hline Niraparib & $\begin{array}{l}\text { Being tested for ovarian and } \\
\text { breast cancers and Ewing } \\
\text { sarcoma }\end{array}$ & Phase III & $\begin{array}{l}\text { Phase III trial for Niraparib monotherapy } \\
\text { in patients with HER2 negative, BRCA1/2 } \\
\text { mutated breast cancer currently } \\
\text { recruiting } \\
\text { Phase II trial for Niraparib monotherapy } \\
\text { in patients with ovarian cancer following } \\
\geq 3 \text { chemotherapy treatments currently } \\
\text { recruiting }\end{array}$ & [159-161] \\
\hline
\end{tabular}

Rucaparib, CEP9722, and BMN673 are all undergoing clinical trials to oversee their potential for treating common $B R C A$ associated cancers (Table 1) [17-21]. Several other PARP inhibitors that are mentioned in this review are being used in in vitro studies but have not yet been tested clinically.

In spite of the push to develop PARP inhibitors, opportunities for their optimal application remain largely unclarified.
While defects in HR pathways signify opportunities for synthetic lethality, there is a push to look beyond $B R C A$ mutational status to assess HR dysfunction, especially since only $15 \%$ of ovarian epithelial cancers are deficient in HR due to mutations of $B R C A 1 / 2[22,23]$ and only $5-10 \%$ of breast and ovarian cancers are associated with $B R C A$ germline mutation [24]. Meanwhile, it is increasingly apparent that HR 
defects are not always predicted by germline BRCA status. For example, several phase II clinical trials that stratified patients according to $B R C A 1 / 2$ germline mutational status showed less than $50 \%$ objective response rate (ORR) to Olaparib compared to control $[25,26]$. It appears that a significant subset of sporadic cancers with "BRCAness," a $B R C A$-like phenotype resulting from $\mathrm{HR}$ deficiencies, are also hypersensitive to PARP inhibitors. For example, Gelmon et al. showed that a significant fraction of ovarian and breast cancer patients with an intact BRCA gene responded to PARP inhibitors [27]. However, this expanded arsenal for PARP inhibitor therapy will remain untapped unless effective strategies are in place for patient stratification. Given the fact that BRCAness is a prerequisite for hypersensitivity to PARP inhibitors, the optimization of synthetic lethality relies on having biomarkers to predict BRCAness.

In this review, we detail select predictive and modulatory biomarkers for PARP inhibitors of clinical-translational significance that will help reap the benefits of personalized cancer therapy.

\section{Biomarkers in the HR Pathway}

2.1. Partner and Localizer of BRCA2 (PALB2). PALB2 is a tumor suppressor [28] and binding partner of BRCA2 that facilitates the nuclear localization and HR capabilities of BRCA2 [28]. During HR, PALB2 association with RAD51 and DNA stimulates strand invasion [28]. Mutations in PALB2 have been demonstrated in $1.1 \%$ of patients with familial breast cancer [29] and the c.1592delT frameshift mutation has been linked to a 6-fold increase in likelihood of developing breast cancer [30]. PALB2 mutations were also identified in $0.6 \%$ of patients with familial pancreatic cancer [31]. PALB2-deficient lymphoblasts EUFA1341 cells displayed increased cytotoxicity in response to Olaparib compared to their controls [28]. Due to the fact that PALB2 helps to regulate $\mathrm{BRCA} 2 / \mathrm{RAD} 51-$ mediated $\mathrm{HR}$ and has demonstrated its ability to induce synthetic lethality in the presence of PARP inhibition, PALB2 deficiency in tumors is an interesting prospect for future clinical trials regarding PARP inhibitor sensitivity.

2.2. Fanconi Anemia (FA) Complementation Group (FANC). FANC members include FANCD1 (BRCA2), FANCD2, FNAC31, and FANCN and play a major role in HR [32]. These proteins are related by their common association in a nuclear complex. After DNA damage, activation of the FA repair pathway involves the colocalization of FANCD2 with BRCA1 [33] in a manner dependent on monoubiquitination [34]. Thus, the functional biomarker of the FA pathway activation is nuclear FA protein/BRCA foci formation. The impairment of nuclear FA protein/BRCA foci formation after DNA damage is a powerful method for assessing functionality of the FA repair pathway $[32,35]$ and an important biomarker for HR defects. Powerful metrics are available to detect FANCD2/BRCA1 foci formation, such as the FA triplestaining immunofluorescence based method (FATSI), which identified a subset of non-small-cell lung cancer (NSCLC) tumors that were deficient in FANCD2/BRCA1 foci and thus were repair deficient [32]. Subsequently, these NSCLC cells were hypersensitive to Veliparib, BMN673, and ABT263 [32]. It was also shown that HeLa cervical cancer cells with defective FANCD2, FANCA, or FANCC exhibited cellular hypersensitivity to KU0058948 [4]. Thus, deficient FANCD2 manifested by absent foci formation after DNA damage may be a valuable biomarker to predict PARP inhibitor sensitivity.

2.3. Rad51. Rad51 is crucial for repair of DSBs via the HR pathway. RAD51 nucleates on single-stranded DNA molecules (ssDNA), which initiates the search for its homologous sequence and strand invasion $[32,36]$. RAD51 also interacts with PALB2, BRCA1, and BRCA2 during HR [37, 38]. Formation of RAD51 nuclear foci in response to DNA damage is a functional biomarker for intact $\operatorname{HR}[39,40]$ and lack of foci predicts deficient HR and breast cancer sensitivity to chemotherapy $[35,41]$. Graeser et al. showed that sporadic breast cancers with lower Rad51 scores (Rad51 foci formation following anthracycline-based chemotherapy) showed decreased HR and increased sensitivity to anthracyclinebased chemotherapy [42]. Furthermore, Rad51 paralog C deficiency caused Olaparib sensitivity in a gastric cancer xenograft model [43]. Increased sensitivity to KU0058948 was also observed in HeLa cells with deficient Rad51 and Rad54 [4]. Mukhopadhyay et al. demonstrated that 93\% of ovarian cancer cells that showed no increase in Rad51 foci upon exposure to Rucaparib, and thus had deficient HR, subsequently showed cytotoxicity. Conversely, ovarian cancer cells that showed increased Rad51 foci, and thus had adequate HR, did not demonstrate cytotoxicity [44]. These results show that lack of Rad51 foci in response to DNA damage is a predictor of defective HR and thus can predict sensitivity to PARP inhibition.

\section{Biomarkers in the DDR Pathways}

3.1. Ataxia Telangiectasia Mutated (ATM). ATM is autophosphorylated on Ser1981 in response to DNA DSBs and phosphorylates several proteins within the nucleus of mitotic cells, including BRCA1, p53, CHK2, RAD17, and RAD9, resulting in DSB repair and arrest of the cell cycle [45]. McCabe et al. showed that HeLa cells treated with an ATM kinase inhibitor or siRNA targeting ATM were hypersensitive to KU0058948 [4]. Furthermore, Williamson et al. showed that Granta519 and UPN2 mantle cell lymphoma cells with low ATM expression levels were hypersensitive to Olaparib compared to their controls [46]. Interestingly, ATM deficiency predicted PARP1 inhibitor sensitivity in p53-null gastric cancer cells, and it was speculated that combined inhibition of ATM and PARP1 is a potential therapy for $p 53$-disrupted gastric cancer [47].

3.2. Serine-Threonine Protein Phosphatase (PP2A). PP2A is a phosphatase in the Ser/Thr protein family with 4 regulatory subunits, PPP2R2A, PPP2R2D, PPP2R5A, and PPP2R3C. It is vital to DSB repair and activation of cell cycle checkpoints due to DNA damage [48] but has also been shown to negatively regulate ATM, $\mathrm{CHK} 1 / 2$, and other proteins necessary for DSB 
repair [48]. This may be explained by the fact that different PP2A complexes have different functions at different points of the repair process [48]. PPP2R2A dephosphorylates ATM at S367, S1893, and S1981, which mediates its retention at sites of DSBs and facilitates HR [48]. Kalev et al. showed that $40 \%$ of NSCLCs exhibited decreased PPP2R2A levels and consequently had increased phosphorylation of ATM at S1981, decreased retention at sites of DSBs, and decreased HR [48]. Also, HeLa cells treated with shRNAs specific for PPP2R2A and lung carcinoma cell lines with intrinsically decreased levels of PPP2R2A showed increased sensitivity to Veliparib in comparison to their respective controls [48]. These facts demonstrate the importance of PPP2R2A in maintaining ATM function integrity and the potential usage of decreased PPP2R2A expression as a predictor of PARP inhibitor sensitivity.

3.3. Mre11. Mrell is part of the Mrell-Rad50-Nbs1 (MRN) complex, which contributes to DSB sensing and scaffolding of HR effector proteins at DSB sites [49]. Deficiency in MRE11 is commonly found in endometrial cancer, and Koppensteiner et al. found that these MRE11-deficient endometrial cancers are hypersensitive to BMN673 [50]. Loss of Mre11 in head and neck cancer cells confers hypersensitivity to GPI15427 both in vitro and in vivo using a mouse xenograft [51]. Furthermore, Cal51 breast cancer cells [50] and various acute myeloid leukemia (AML) cell lines [52] with deficient Mrell showed hypersensitivity to KU58948 and BMN673, respectively.

3.4. Tumor Protein p53 (TP53). TP53 is a tumor suppressor in the DDR pathway that causes transient cell cycle arrest, senescence, and apoptosis in response to DNA damage [53]. Almost all BRCA1-mutated breast cancers have a deleterious TP53 mutation, resulting from genomic instability-mediated complex and truncating mutations [54]. This suggests that TP53 deficiency may represent a biomarker for BRCAness and hypersensitivity to PARP inhibitors [54, 55]. Furthermore, over $90 \%$ of basal-like breast cancers (triple-negative, high-grade breast carcinomas) have a deleterious TP53 mutation and exhibit a molecular phenotype reminiscent of BRCA1-deficient breast cancer [54]. A recent study showed that depletion of TP53 in various breast cancer cell lines displayed hypersensitivity to the PARP inhibitor IQD in comparison to their respective controls [56].

3.5. $\gamma H 2 A X . \gamma \mathrm{H} 2 \mathrm{AX}$ is a variant of the $\mathrm{H} 2 \mathrm{~A}$ histone family that is phosphorylated on Ser139 by ATM and ATM-Rad3related (ATR) in the PI3K pathway of DNA repair and functions to recruit other DNA repair proteins in response to DNA damage $[57,58]$. Importantly, $\gamma \mathrm{H} 2 \mathrm{AX}$ foci form in response to DSBs [57], and the presence of foci can be utilized as a biomarker to measure DNA damage induced by PARP inhibition [59]. BRCA1-mutated acute myeloid leukemia cells that were exposed to Olaparib subsequently formed $\gamma \mathrm{H} 2 \mathrm{AX}$ foci, suggesting that $\gamma \mathrm{H} 2 \mathrm{AX}$ foci formation may be a useful biomarker for successful PARP inhibition [59]. Furthermore, there have been two completed phase I trials for Veliparib in which investigators found that $\gamma \mathrm{H} 2 \mathrm{AX}$ was a reliable biomarker to measure sensitivity to PARP inhibition of circulating tumor cells of metastatic solid tumors or lymphomas $[60,61]$.

\section{Biomarkers in the BER Pathway}

4.1. Poly(ADP-Ribose) (PAR). PAR chains are linear and branched chains of up to 200 ADP-ribose units whose formation is catalyzed by PARP1/2 [62, 63]. PARPs play a significant role in BER, and PARylation acts as a specific indicator of PARP activity in DNA repair. PARylation also plays a role in chromatin modification, transcription, telomere cohesion, cell death, insulator function, mitotic apparatus function, and energy metabolism $[62,64]$, which affect genome stability, inflammation, neuronal function, aging, and carcinogenesis [64]. A subset of head and neck cancers has an elevation in basal PARylation [65]. Interestingly, head and neck cancer cells with elevated PAR are hypersensitive to Veliparib [65], suggesting that high PAR levels predict sensitivity to PARP inhibition. Further studies should be done to determine the significance of elevated PAR in different tumors.

4.2. PARP1-Binding Protein (PARP-BP). PARP1-binding protein (PARP-BP) is encoded by the gene C12orf48 and directly interacts with PARP1 to enhance its activity and the repair of DNA breaks [66]. Its expression is upregulated in pancreatic ductal adenocarcinomas (PDACs) and a number of other malignancies, which indicates increased PARP activity. Knockdown of C12orf48 in PDACs decreased PARP-BP expression, which subsequently caused decreased PARP1 activity and cell viability, while increasing sensitivity to Adriamycin, UV irradiation, and hydrogen peroxide [66]. This highlights the importance of PARP1 activity in the viability of PDACs with upregulated PARP-BP and should be further explored to determine if these tumors may be hypersensitive to PARP inhibitors.

4.3. X-Ray Repair Cross-Complementing 1 (XRCC1). XRCC1 is a key player in the DNA BER pathway, which is recruited in response to PAR chain formation at SSB sites by PARP1 [67]. $X R C C 1$ is deficient in $16 \%$ of breast cancers and is associated with high grade, triple negativity, loss of hormone receptors, and basal-like breast cancers [68]. XRCC1-deficient Chinese hamster ovary (CHO) EM9 cells showed accumulation of SSBs [67] and were hypersensitive to PARP inhibitors due to the supplementary effect of PARP inhibitors in preventing DNA ligation [67]. Mouse fibroblasts deficient in XRCC1 were hypersensitive to the PARP inhibitor 4-amino-1,8naphthalimide (4-AN) [69], and XRCC1 knockdown breast cancer cells were hypersensitive to KU0058948 [70].

\section{5. "Other" Biomarkers}

Lastly, there are other proteins and abnormalities in DNA expression that do not play a direct role in HR or DDR but can indirectly affect the process. These "other biomarkers" indirectly affect DNA repair through regulation of BRCA1/2, ATM, or other proteins responsible for its execution. Thus, 
their abnormal expression may be predictive biomarker for PARP inhibitor sensitivity.

5.1. E26 Transformation Specific or E-Twenty-Six (ETS). ETS genes belong to a large family of transcription factors that regulate cell differentiation, proliferation, migration, cell cycle control, apoptosis, invasion, and angiogenesis [71, 72]. ETS gene fusions occur widely in many cancers including Ewing's sarcoma, acute myeloid leukemia (AML), and prostate cancer [73]. Baker et al. found that ETS-2 complexes with components of SWI/SNF repress BRCA1 in MCF7 cells [74]. ETS-1 expression is a poor prognostic marker for breast, lung, colorectal, and ovarian cancer $[71,75,76]$. Interestingly, Legrand et al. revealed that ETS-1 activates the catalytic activity of PARP1, which then PARylates ETS-1 [76], revealing a novel link between ETS-1 and DDR pathways. They also found that PARP inhibition upregulates ETS-1 transcriptional activity and led to its nuclear accumulation and selective cytotoxicity in ETS-1 expressing HeLa cells [76]. This suggests that nuclear ETS-1 expression may be a predictive biomarker for PARP inhibitor sensitivity. However, in a phase 1 doseescalation study, no correlation was found between ETS gene rearrangement and sensitivity to Niraparib in prostate cancer [20]. Further studies should be performed to determine the significance of nuclear ETS-1 expression in PARP inhibitor sensitivity.

5.2. Transforming Growth Factor $\beta$ (TGF $\beta$ ). TGF $\beta$ is a cytokine whose presence at tumor sites has classically been associated with poor prognosis [77]. TGF $\beta$ has been shown to inhibit the expression of ATM, mutS homolog 2 (MSH2), and BRCA1 in BT474 breast cancer cells through microRNA, specifically the miR-181 family [77], inducing a BRCAness phenotype. Similarly, treatment of MDA-MB-231, MDAMB-468, and BT474 breast cancer cells with TGF $\beta$ caused increased sensitivity to Veliparib [77]. Thus, the presence of increased TGF $\beta$ signaling may be an indicator of BRCAness and subsequent hypersensitivity to PARP inhibition.

5.3. MicroRNAs (miRNAs). miRNAs are small noncoding RNAs that mediate posttranscriptional repression and degradation of mRNA transcripts [77, 78]. Usage of miRNA is an effective and clinically tolerable method for inducing BRCAness and hypersensitivity to PARP inhibitors. The miR181 family is induced by TGF $\beta$ to suppress ATM, MSH2, and BRCA, promoting BRCAness, as previously described [77]. Furthermore, more aggressive breast cancers exhibited increased expression of miR-181 [79]. Similarly, miR-182 downregulates $B R C A 1$ expression in various breast cancer cell lines in vitro and in vivo, resulting in defective HRmediated repair and increased sensitivity to irradiation and Olaparib [80]. Mouse xenograft of MDA-MB-231 cells stably expressing miR-182 showed increased PARP inhibitor sensitivity to 4-amino-1,8-naphalamide (ANI) and Veliparib compared to their controls [80]. miR-103 and miR-107 target Rad51 and inhibit formation of Rad51 foci in response to DNA damage in osteosarcoma cells [81, 82] and subsequently increase sensitivity to Olaparib [81]. Furthermore, it was demonstrated that ovarian cancer cells with high levels of hsa-miR-107 were sensitive to Olaparib, and inhibition of hsamiR-107 eliminated this sensitivity. Similarly, overexpression of miR-96 in osteosarcoma U2OS cells reduced the levels of Rad51 by directly targeting its coding region [83], decreasing the efficiency of HR and enhancing sensitivity to Olaparib.

5.4. Lysine-Specific Demethylase 1 (LSD1). LSD1 is an epigenetic regulator of gene expression that demethylates histones $\mathrm{H} 3 \mathrm{~K} 4$ and $\mathrm{H} 3 \mathrm{~K} 9$ [84]. LSD1 regulates genes associated with proliferation including those for $\mathrm{p} 21, \mathrm{ErbB} 2$, and Cyclin A2 [84]. LSD1 is upregulated in many cancers and is a predictive biomarker for aggressive biology in breast cancer and prostate cancer [84]. Increased LSD1 levels show a positive correlation with progression, proliferation, and invasion of breast cancer cells [85], and pharmacological inhibition of LSD1 results in growth inhibition [84]. One study found that LSD1 is recruited to sites of DNA damage in a manner dependent on Ring Finger Protein 168 (RNF168), suggesting its potential role in DDR downstream of RNF168 [86]. Interestingly, ectopic expression of LSD1 in basal-like breast cancer cells promoted downregulation of BRCAl and hypersensitivity to Olaparib [87]. Thus, because LSD1 is upregulated in various cancers, including breast and prostate, and there is preliminary evidence of LSD1-dependent BRCA1 suppression and PARP inhibitor sensitivity, further clinical validation is required to explore LSD1 as an official biomarker for responsiveness to PARP inhibitor.

5.5. Cyclin-Dependent Kinase 12 (CDK12). CDK12 is a kinase that regulates cell cycle checkpoints and positively regulates BRCA1 [88]. It is mutated in nearly $3 \%$ of high-grade serous ovarian cancers, resulting in reduced BRCA1 levels and compromised HR repair. CDK12 is also a key regulator in the transcription of several other genes involved in DNA repair including ATM/ATR, FANCL, and BRCA2 [89]. As such, tumors with mutated CDK12 should show "BRCAness" and are candidates for PARP inhibitor therapy [90]. A study has shown that CDK12-deficient ovarian cancer cells are more sensitive to Veliparib compared to their controls [90]. Furthermore, serous ovarian carcinoma cells with mutated CDK12 exhibit hypersensitivity to Olaparib [91], platinum derivatives, and alkylating agents [89]. This provides evidence that CDK12-deficient ovarian cancers could be targets for PARP inhibitor therapy, and further work should be done to evaluate PARP inhibitor efficacy in other CDK12-deficient tumors.

5.6. Transforming Acidic Coiled-Coil Containing Protein 3 (TACC3). TACC3 is a member of the TACC family, which consists of proteins that localize at centrosomes to facilitate microtubule assembly and stabilization, enabling chromosomal integrity during mitosis [92]. TACC3 has been shown to regulate microtubule nucleation by interacting with $\gamma$-tubulin ring complex proteins [93] and promoting plus-end microtubule growth [94]. Both upregulation and downregulation of TACC 3 are found in human solid tumors $[95,96]$. Silencing of TACC 3 results in microtubule destabilization and chromosome misalignment [92]. Overexpression of TACC3 has 
been shown to lead to accumulation of DSBs and negative regulation of $A T M$ and subsequent DDR signaling in U2OS cells [97]. Overexpression of TACC 3 also impairs HR, NHEJ, and normal cell cycle checkpoint function in U2OS cells [97]. Moreover, it was found that nontumorigenic human mammary epithelial MCF10A cells with elevated levels of TACC3 showed hypersensitivity to Olaparib and NU1025 [97], suggesting its potential role in conferring synthetic lethality. Further studies with different cell lines should be employed to determine the role of TACC 3 overexpression in conferring hypersensitivity to PARP inhibition.

5.7. Aurora Kinase A (Aur A). Aur A is a protein kinase necessary for construction of the mitotic spindle [98] and phosphorylates cell division cycle 25 homolog B (CDC25B) at the G2/M checkpoint, causing CDK1 activation and mitotic entry [99]. Cazales et al. showed that, during DNA damageinduced activation of the G2/M checkpoint, Aur A was not activated, and the cell cycle did not progress in U2OS cells [99]. However, ectopic expression of activated Aur A resulted in a bypass of this checkpoint [99]. Aur A is overexpressed in various solid tumors, including ovarian cancer [100], cervical cancer [101], and colon cancer [102]. Sourisseau et al. demonstrated that overexpression of Aur A impairs formation of Rad51 foci in MCF10A cells and HR in human embryonic kidney 293 (HEK293) cells. Overexpression of Aur A in PIR12 (Capan 1-derived PARP inhibitor resistant cell line) also induced sensitivity to KU0058948 [98]. Taken together, these data suggest that Aur A overexpression may predict sensitivity to PARP inhibition.

5.8. Phosphatase and Tensin Homolog (PTEN). PTEN is a tumor suppressor that inactivates the P13K/AKT pathway whose signaling is important for propagation of the cell cycle [103]. PTEN deficiency is associated with many malignancies, including breast [104] and prostate cancers [105], and disrupts chromosomal integrity by causing centromere breakage and translocations [106]. Mendes-Pereira et al. showed that PTEN deficiency leads to impairment of HR, which subsequently leads to increased sensitivity to KU0058948 in HCT116 colorectal carcinoma and HEC1A endometrial adenocarcinoma cells [107]. There are numerous reports of PTEN-deficient cancer cell lines that show decreased Rad51 levels [106, 107] and increased nuclear H2AX foci [106, 108, 109], suggesting deficient HR that leads to accumulation of foci. Furthermore, Shen et al. showed that PTEN potentiates activation of the Rad51 promoter by E2F-1 in PC3 prostate cancer cells [106]. However, Fraser et al. showed that PTEN-deficient prostate cancer cells do not have decreased Rad51, have sufficient HR, and are insensitive to PARP inhibitors [108, 110]. This discrepancy may be explained by the fact that prostate cancer cells with an intrinsically null PTEN genotype have other genomic aberrations that are not present in prostate cancer cells with experimentally silenced PTEN, which can cause different behaviors [111]. Regardless, further studies should be pursued to examine the role of PTEN in HR in prostate cancer to determine its utility as a biomarker for predicting PARP inhibitor sensitivity.
5.9. Mitochondrial DNA (mtDNA). There is emerging evidence linking mtDNA depletion with BRCA2 depletion. mtDNA is depleted in breast, prostate, and thyroid transformed cells [112], which promotes activation of calcineurin/PI3Kinase/AKT signaling that causes upregulation of miR-1245 and ubiquitin ligase Skp2, negative regulators of BRCA2 [112]. This promoted HR deficiency and increased sensitivity to Rucaparib [112]. Further studies with a larger sample size are needed to further validate this promising correlation and to determine whether mtDNA depletion can be used as a biomarker for PARP inhibitor sensitivity.

5.10. Genomic Scar. A genomic scar is defined as a genomic abnormality [113] that is present in a wide variety of cancers, including breast, ovarian, pancreatic, esophagus, lung, and prostate cancers [113]. Several known genomic scars have been associated with BRCA1/2 dysfunction and homologous repair dysfunction [113]. Telomeric allele imbalance $\left(N_{\mathrm{tAi}}\right)$, loss of heterozygosity $(\mathrm{LOH})$ clustering, mutational signature 3 (mutational signature D), and total number of somatic, synonymous, and nonsynonymous coding mutations $\left(N_{\text {mut }}\right)$ are genomic scars that are predictive of BRCA1/2 dysfunction [113] and thus may predict responsiveness to PARP inhibitors. Homologous recombination defects (HRD) and large-scale transitions are genomic scars predictive of general HR dysfunction and may also indicate responsiveness to PARP inhibitors [113-116]. Further studies to evaluate the direct relationship between these genomic scars and sensitivity to PARP inhibitors should be performed.

\section{Discussion}

It is accepted that PARP inhibition mediates synthetic lethality in tumors with inherited BRCA deficiencies [117] and that BRCA1 hypermethylation can predict sensitivity to PARP inhibition [118-121]. However, it is increasingly clear that deficient $B R C A 1 / 2$ germline status is not enough to predict PARP inhibitor sensitivity $[48,122-124]$. This growing sense is supported by clinical trials, which have shown that not all BRCA1 mutation carriers are responsive to PARP inhibition $[26,125]$. Altogether, these results further underline the need for nuanced biomarkers predictive of PARP inhibitor hypersensitivity. This entails a paradigm shift away from reliance on single predictive biomarkers for PARP inhibitor hypersensitivity (such as deficient BRCAl gene status) and towards the idea of predictive algorithms and biomarker codes that characterize various manifestations of "BRCAness" [126].

Additionally, we need to understand the roles of PARP1/2 outside of BER that contribute to the "off-target" effects of PARP inhibition, which induce cytotoxicity through mechanisms separate from dysfunctional HR repair, and can modulate or amplify the net synthetic lethal effect of PARP inhibitors. Even though synthetic lethality is mediated by PARP inhibition, not all benefits of PARP inhibitors are mediated through defects in HR repair. For example, while the canonical role of PARP is through the DNA damage repair pathway, PARP also plays a role in various networks including tumor-promoting inflammation, cell cycle 
checkpoint regulation, senescence, angiogenesis, epithelialmesenchymal transition (EMT), PARylation and remodeling of chromatin during transcription, and programmed cell death and metastasis [14, 127-130]. These off-target mechanisms may modulate the tumor microenvironment through a scenario known as "contextual" synthetic lethality that further sensitizes tumor cells to PARP inhibition [131]. This concept is exemplified in the emerging link between PARP inhibition and suppression of angiogenesis [130, 132134]. Interestingly, hypoxic conditions deregulate DNA repair pathways and promote genomic instability through deregulation of BRCA1/2 [135-137]. Meanwhile, it is also postulated that PARP inhibitors inhibit BER to cause transient stalling of replication forks that degenerate into DSBs [138, 139].

It is also important to consider the way PARP inhibition relates to nononcogenic addiction, which is defined as the hyperreliance on secondary regulatory pathways in response to stressful conditions brought on by oncogene activation and tumor progression $[140,141]$. Interestingly, nononcogenic addiction may represent underlying $\mathrm{HR}$ defects that can be targeted through synthetic lethality. For example, elevated PAR levels indicate PARP hyperactivity in response to underlying HR defects $[65,142,143]$. Thus, high PAR levels may indicate compensatory dependence on the BER pathway and therefore hypersensitivity to PARP inhibition [144]. As such, awareness of nononcogenic addiction events may enable us to distinguish between biomarkers of primary HR deficiencies versus biomarkers of secondary compensatory events both of which may predict hypersensitivity to PARP inhibition.

While the contextual parameters of PARP inhibition may be leveraged to our advantage, this may be a double-edged sword due to the addition of a new layer of complexity to the development of predictive biomarkers. For example, increased TGF $\beta$ signaling caused hypersensitivity to PARP inhibition in BT474 but not in MCF7 cells [145]. Meanwhile, knockdown of ATM by siRNA significantly increased sphereforming efficiency (SFE) in BT474 and MDA361 but not in MCF7 cells. While these variations showcase the cell typedependent outcomes of ATM regulation by TGF $\beta$ [146], they also highlight the possibility that contextual variables may inflate the perceived efficacy of PARP inhibition. Awareness of such possibilities helps guard against falsely attributing net cytotoxic effects to a single biomarker, since the observed efficacy of PARP inhibition may really be the sum effect of multiple mechanisms, not necessarily all due to synthetic lethality due to HR defects.

It is crucial to proceed with caution when identifying candidate predictive biomarkers. One example is the upregulation of EMSY, a putative oncogene that transcriptionally silences exon 3 of BRCA2 that links the BRCA2 pathway to sporadic breast and ovarian cancer [147]. It was suggested that because EMSY amplification could mimic a BRCA2 mutated state [148], it could account for BRCAness in sporadic breast and ovarian cancers with intact BRCA2 [122] and possibly predict hypersensitivity to PARP inhibitors. However, it was recently shown that cells with an amplified EMSY had the same RAD51 foci formation efficacy, as well as sensitivity to PARP inhibitors, as cells without EMSY amplification [149]. Taken together, these results underscore the importance of triangulating BRCAness through a variety of biomarkers in order to detect opportunities for synergism, avoid conflation of various cytotoxic mechanisms, and customize treatment.

\section{Competing Interests}

The authors declare that they have no competing interests.

\section{Authors' Contributions}

Stephen Murata and Catherine Zhang contributed equally to the paper.

\section{References}

[1] Y. Liang, S.-Y. Lin, F. C. Brunicardi, J. Goss, and K. Li, "DNA damage response pathways in tumor suppression and cancer treatment," World Journal of Surgery, vol. 33, no. 4, pp. 661-666, 2009.

[2] T. Helleday, E. Petermann, C. Lundin, B. Hodgson, and R. A. Sharma, "DNA repair pathways as targets for cancer therapy," Nature Reviews Cancer, vol. 8, no. 3, pp. 193-204, 2008.

[3] H. Tian, Z. Gao, H. Li et al., "DNA damage response-a doubleedged sword in cancer prevention and cancer therapy," Cancer Letters, vol. 358, no. 1, pp. 8-16, 2015.

[4] N. McCabe, N. C. Turner, C. J. Lord et al., "Deficiency in the repair of DNA damage by homologous recombination and sensitivity to poly(ADP-ribose) polymerase inhibition," Cancer Research, vol. 66, no. 16, pp. 8109-8115, 2006.

[5] W. G. Kaelin Jr., "The concept of synthetic lethality in the context of anticancer therapy," Nature Reviews Cancer, vol. 5, no. 9, pp. 689-698, 2005.

[6] S. D. Merajver, T. S. Frank, J. Xu et al., "Germline BRCA1 mutations and loss of the wild-type allele in tumors from families with early onset breast and ovarian cancer," Clinical Cancer Research, vol. 1, no. 5, pp. 539-544, 1995.

[7] K. Yoshida and Y. Miki, "Role of BRCA1 and BRCA2 as regulators of DNA repair, transcription, and cell cycle in response to DNA damage," Cancer Science, vol. 95, no. 11, pp. 866-871, 2004.

[8] H. Konishi, M. Mohseni, A. Tamaki et al., "Mutation of a single allele of the cancer susceptibility gene BRCA1 leads to genomic instability in human breast epithelial cells," Proceedings of the National Academy of Sciences of the United States of America, vol. 108, no. 43, pp. 17773-17778, 2011.

[9] K. Yata, J.-Y. Bleuyard, R. Nakato et al., "BRCA2 coordinates the activities of cell-cycle kinases to promote genome stability," Cell Reports, vol. 7, no. 5, pp. 1547-1559, 2014.

[10] S. M. H. Sy, M. S. Y. Huen, and J. Chen, "PALB2 is an integral component of the BRCA complex required for homologous recombination repair," Proceedings of the National Academy of Sciences of the United States of America, vol. 106, no. 17, pp. 7155$7160,2009$.

[11] J. H. Houtgraaf, J. Versmissen, and W. J. van der Giessen, "A concise review of DNA damage checkpoints and repair in mammalian cells," Cardiovascular Revascularization Medicine, vol. 7, no. 3, pp. 165-172, 2006.

[12] A. Ashworth, "A synthetic lethal therapeutic approach: poly(ADP) ribose polymerase inhibitors for the treatment of cancers deficient in DNA double-strand break repair," Journal of Clinical Oncology, vol. 26, no. 22, pp. 3785-3790, 2008. 
[13] C. Underhill, M. Toulmonde, and H. Bonnefoi, "A review of PARP inhibitors: from bench to bedside," Annals of Oncology, vol. 22, no. 2, pp. 268-279, 2011.

[14] B. Lupo and L. Trusolino, "Inhibition of poly(ADPribosyl)ation in cancer: old and new paradigms revisited," Biochimica et Biophysica Acta (BBA)-Reviews on Cancer, vol. 1846, no. 1, pp. 201-215, 2014.

[15] T. Helleday, "The underlying mechanism for the PARP and BRCA synthetic lethality: clearing up the misunderstandings," Molecular Oncology, vol. 5, no. 4, pp. 387-393, 2011.

[16] S. Tangutoori, P. Baldwin, and S. Sridhar, "PARP inhibitors: a new era of targeted therapy," Maturitas, vol. 81, no. 1, pp. 5-9, 2015.

[17] S. Kummar, A. M. Oza, G. F. Fleming et al., "Randomized trial of oral cyclophosphamide and veliparib in high-grade serous ovarian, primary peritoneal, or fallopian tube cancers, or BRCA-mutant ovarian cancer," Clinical Cancer Research, vol. 21, no. 7, pp. 1574-1582, 2015.

[18] J. F. Liu, P. A. Konstantinopoulos, and U. A. Matulonis, "PARP inhibitors in ovarian cancer: current status and future promise," Gynecologic Oncology, vol. 133, no. 2, pp. 362-369, 2014.

[19] T. D. Penning, G.-D. Zhu, V. B. Gandhi et al., "Discovery of the Poly(ADP-ribose) polymerase (PARP) inhibitor 2-[(R)2-methylpyrrolidin-2-yl]-1H-benzimidazole-4-carboxamide (ABT-888) for the treatment of cancer," Journal of Medicinal Chemistry, vol. 52, no. 2, pp. 514-523, 2009.

[20] S. K. Sandhu, W. R. Schelman, G. Wilding et al., "The poly(ADPribose) polymerase inhibitor niraparib (MK4827) in BRCA mutation carriers and patients with sporadic cancer: a phase 1 dose-escalation trial," The Lancet Oncology, vol. 14, no. 9, pp. 882-892, 2013.

[21] M. Ihnen, C. Z. Eulenburg, T. Kolarova et al., "Therapeutic potential of the poly(ADP-ribose) polymerase inhibitor rucaparib for the treatment of sporadic human ovarian cancer," Molecular Cancer Therapeutics, vol. 12, no. 6, pp. 1002-1015, 2013.

[22] M. E. Moynahan, J. W. Chiu, B. H. Koller, and M. Jasint, "Brcal controls homology-directed DNA repair," Molecular Cell, vol. 4, no. 4, pp. 511-518, 1999.

[23] M. E. Moynahan, A. J. Pierce, and M. Jasin, "BRCA2 is required for homology-directed repair of chromosomal breaks," Molecular Cell, vol. 7, no. 2, pp. 263-272, 2001.

[24] R. Wooster, S. L. Neuhausen, J. Mangion et al., "Localization of a breast cancer susceptibility gene, BRCA2, to chromosome 13q12-13," Science, vol. 265, no. 5181, pp. 2088-2090, 1994.

[25] B. Kaufman, R. Shapira-Frommer, R. K. Schmutzler et al., "Olaparib monotherapy in patients with advanced cancer and a germline BRCA1/2 mutation," Journal of Clinical Oncology, vol. 33, no. 3, pp. 244-250, 2015.

[26] A. Tutt, M. Robson, J. E. Garber et al., "Oral poly(ADPribose) polymerase inhibitor olaparib in patients with BRCA1 or BRCA2 mutations and advanced breast cancer: a proof-ofconcept trial," The Lancet, vol. 376, no. 9737, pp. 235-244, 2010.

[27] K. A. Gelmon, M. Tischkowitz, H. Mackay et al., "Olaparib in patients with recurrent high-grade serous or poorly differentiated ovarian carcinoma or triple-negative breast cancer: a phase 2, multicentre, open-label, non-randomised study," The Lancet Oncology, vol. 12, no. 9, pp. 852-861, 2011.

[28] R. Buisson, A.-M. Dion-Côté, Y. Coulombe et al., "Cooperation of breast cancer proteins PALB2 and piccolo BRCA2 in stimulating homologous recombination," Nature Structural and Molecular Biology, vol. 17, no. 10, pp. 1247-1254, 2010.
[29] N. Rahman, S. Seal, D. Thompson et al., "PALB2, which encodes a BRCA2-interacting protein, is a breast cancer susceptibility gene," Nature Genetics, vol. 39, no. 2, pp. 165-167, 2007.

[30] K. Obermeier, J. Sachsenweger, T. W. P. Friedl, H. Pospiech, R. Winqvist, and L. Wiesmüller, "Heterozygous PALB2 c.1592delT mutation channels DNA double-strand break repair into errorprone pathways in breast cancer patients," Oncogene, vol. 35, pp. 3796-3806, 2016.

[31] D. B. Zhen, K. G. Rabe, S. Gallinger et al., "BRCA1, BRCA2, PALB2, and CDKN2A mutations in familial pancreatic cancer: a PACGENE study," Genetics in Medicine, vol. 17, no. 7, pp. 569577, 2015.

[32] W. Duan, L. Gao, B. Aguila, A. Kalvala, G. A. Otterson, and M. A. Villalona-Calero, "Fanconi anemia repair pathway dysfunction, a potential therapeutic target in lung cancer," Frontiers in Oncology, vol. 4, article 368, 2014.

[33] I. Garcia-Higuera, T. Taniguchi, S. Ganesan et al., "Interaction of the Fanconi anemia proteins and BRCAl in a common pathway," Molecular Cell, vol. 7, no. 2, pp. 249-262, 2001.

[34] X. Wang, P. R. Andreassen, and A. D. D'Andrea, "Functional interaction of monoubiquitinated FANCD2 and BRCA2/FANCD1 in chromatin," Molecular and Cellular Biology, vol. 24, no. 13, pp. 5850-5862, 2004.

[35] H. Willers, A. G. Taghian, C.-M. Luo, A. Treszezamsky, D. C. Sgroi, and S. N. Powell, "Utility of DNA repair protein foci for the detection of putative BRCA1 pathway defects in breast cancer biopsies," Molecular Cancer Research, vol. 7, no. 8, pp. 1304-1309, 2009.

[36] M. R. G. Taylor, M. Špírek, K. R. Chaurasiya et al., "Rad51 paralogs remodel pre-synaptic Rad51 filaments to stimulate homologous recombination," Cell, vol. 162, no. 2, pp. 271-286, 2015.

[37] R. Scully, J. Chen, A. Plug et al., "Association of BRCA1 with Rad51 in mitotic and meiotic cells," Cell, vol. 88, no. 2, pp. 265275, 1997.

[38] L. Pellegrini, D. S. Yu, T. Lo et al., "Insights into DNA recombination from the structure of a RAD51-BRCA2 complex," Nature, vol. 420, no. 6913, pp. 287-293, 2002.

[39] E. Raderschall, E. I. Golub, and T. Haaf, "Nuclear foci of mammalian recombination proteins are located at single- stranded DNA regions formed after DNA damage," Proceedings of the National Academy of Sciences of the United States of America, vol. 96, no. 5, pp. 1921-1926, 1999.

[40] T. Haaf, E. I. Golub, G. Reddy, C. M. Radding, and D. C. Ward, "Nuclear foci of mammalian Rad51 recombination protein in somatic cells after DNA damage and its localization in synaptonemal complexes," Proceedings of the National Academy of Sciences of the United States of America, vol. 92, no. 6, pp. 2298-2302, 1995.

[41] H. Asakawa, H. Koizumi, A. Koike et al., "Prediction of breast cancer sensitivity to neoadjuvant chemotherapy based on status of DNA damage repair proteins," Breast Cancer Research, vol. 12, no. 2, article R17, 2010.

[42] M. Graeser, A. McCarthy, C. J. Lord et al., "A marker of homologous recombination predicts pathologic complete response to neoadjuvant chemotherapy in primary breast cancer," Clinical Cancer Research, vol. 16, no. 24, pp. 6159-6168, 2010.

[43] A. Min, S.-A. Im, Y.-K. Yoon et al., "RAD51C-deficient cancer cells are highly sensitive to the PARP inhibitor olaparib," Molecular Cancer Therapeutics, vol. 12, no. 6, pp. 865-877, 2013.

[44] A. Mukhopadhyay, A. Elattar, A. Cerbinskaite et al., "Development of a functional assay for homologous recombination status 
in primary cultures of epithelial ovarian tumor and correlation with sensitivity to poly(ADP-ribose) polymerase inhibitors," Clinical Cancer Research, vol. 16, no. 8, pp. 2344-2351, 2010.

[45] S. V. Kozlov, A. J. Waardenberg, K. Engholm-Keller, J. W. Arthur, M. E. Graham, and M. F. Lavin, "Reactive Oxygen Species (ROS)-activated ATM-dependent phosphorylation of cytoplasmic substrates identified by large-scale phosphoproteomics screen," Molecular \& Cellular Proteomics, vol. 15, no. 3, pp. 1032-1047, 2016.

[46] C. T. Williamson, H. Muzik, A. G. Turhan et al., "ATM deficiency sensitizes mantle cell lymphoma cells to poly(ADPribose) polymerase-1 inhibitors," Molecular Cancer Therapeutics, vol. 9, no. 2, pp. 347-357, 2010.

[47] E. Kubota, C. T. Williamson, R. Ye et al., "Low ATM protein expression and depletion of p53 correlates with olaparib sensitivity in gastric cancer cell lines," Cell Cycle, vol. 13, no. 13, pp. 2129-2137, 2014.

[48] P. Kalev, M. Simicek, I. Vazquez et al., "Loss of PPP2R2A inhibits homologous recombination DNA repair and predicts tumor sensitivity to PARP inhibition," Cancer Research, vol. 72, no. 24, pp. 6414-6424, 2012.

[49] R. S. Williams, J. S. Williams, and J. A. Tainer, "Mrel1-Rad50Nbs1 is a keystone complex connecting DNA repair machinery, double-strand break signaling, and the chromatin template," Biochemistry and Cell Biology, vol. 85, no. 4, pp. 509-520, 2007.

[50] R. Koppensteiner, E. P. Samartzis, A. Noske et al., "Effect of MRE1l loss on PARP-inhibitor sensitivity in endometrial cancer in vitro," PLoS ONE, vol. 9, no. 6, Article ID e100041, 2014.

[51] S. A. Lajud, D. A. Nagda, T. Yamashita et al., "Dual disruption of DNA repair and telomere maintenance for the treatment of head and neck cancer," Clinical Cancer Research, vol. 20, no. 24, pp. 6465-6478, 2014.

[52] T. J. Gaymes, A. M. Mohamedali, M. Patterson et al., "Microsatellite instability induced mutations in DNA repair genes CtIP and MRE1l confer hypersensitivity to poly (ADPribose) polymerase inhibitors in myeloid malignancies," Haematologica, vol. 98, no. 9, pp. 1397-1406, 2013.

[53] H. C. Reinhardt and B. Schumacher, "The p53 network: cellular and systemic DNA damage responses in aging and cancer," Trends in Genetics, vol. 28, no. 3, pp. 128-136, 2012.

[54] H. Holstege, H. M. Horlings, A. Velds et al., "BRCA1-mutated and basal-like breast cancers have similar aCGH profiles and a high incidence of protein truncating TP53 mutations," BMC Cancer, vol. 10, article 654, 2010.

[55] T. M. Severson, J. Peeters, I. Majewski et al., "BRCA1-like signature in triple negative breast cancer: molecular and clinical characterization reveals subgroups with therapeutic potential," Molecular Oncology, vol. 9, no. 8, pp. 1528-1538, 2015.

[56] I. C. R. Ireno, R. S. T. Wiehe, A. I. U. Stahl et al., "Modulation of the poly (ADP-ribose) polymerase inhibitor response and DNA recombination in breast cancer cells by drugs affecting endogenous wild-type p53," Carcinogenesis, vol. 35, no. 10, pp. 2273-2282, 2014.

[57] Y. Atsumi, Y. Minakawa, M. Ono et al., "ATM and SIRT6/SNF2H mediate transient H2AX stabilization when DSBs form by blocking HUWE1 to allow efficient $\gamma \mathrm{H} 2 \mathrm{AX}$ foci formation," Cell Reports, vol. 13, no. 12, pp. 2728-2740, 2015.

[58] L. J. Kuo and L.-X. Yang, " $\gamma-\mathrm{H} 2 \mathrm{AX}$-a novel biomaker for DNA double-strand breaks," In Vivo, vol. 22, no. 3, pp. 305-309, 2008.

[59] I. Faraoni, M. Compagnone, S. Lavorgna et al., "BRCA1, PARP1 and $\gamma \mathrm{H} 2 \mathrm{AX}$ in acute myeloid leukemia: role as biomarkers of response to the PARP inhibitor olaparib," Biochimica et Biophysica Acta (BBA)_Molecular Basis of Disease, vol. 1852, no. 3, pp. 462-472, 2015.

[60] S. Kummar, J. Ji, R. Morgan et al., "A phase I study of veliparib in combination with metronomic cyclophosphamide in adults with refractory solid tumors and lymphomas," Clinical Cancer Research, vol. 18, no. 6, pp. 1726-1734, 2012.

[61] S. Kummar, A. Chen, J. Ji et al., "Phase I study of PARP inhibitor ABT-888 in combination with topotecan in adults with refractory solid tumors and lymphomas," Cancer Research, vol. 71, no. 17, pp. 5626-5634, 2011.

[62] V. Schreiber, F. Dantzer, J.-C. Amé, and G. De Murcia, "Poly(ADP-ribose): novel functions for an old molecule," Nature Reviews Molecular Cell Biology, vol. 7, no. 7, pp. 517-528, 2006.

[63] C. E. Redon, A. J. Nakamura, Y.-W. Zhang et al., "Histone $\gamma \mathrm{H} 2 \mathrm{AX}$ and poly(ADP-ribose) as clinical pharmacodynamic biomarkers," Clinical Cancer Research, vol. 16, no. 18, pp. 45324542, 2010.

[64] M. Y. Kim, T. Zhang, and W. L. Kraus, "Poly(ADP-ribosyl)ation by PARP-1: 'PAR-laying' NAD+ into a nuclear signal," Genes \& Development, vol. 19, no. 17, pp. 1951-1967, 2005.

[65] S. Nowsheen, J. A. Bonner, and E. S. Yang, "The poly(ADPribose) polymerase inhibitor ABT-888 reduces radiationinduced nuclear EGFR and augments head and neck tumor response to radiotherapy," Radiotherapy and Oncology, vol. 99, no. 3, pp. 331-338, 2011.

[66] L. Piao, H. Nakagawa, K. Ueda et al., "C12orf48, termed PARP1 binding protein, enhances poly(ADP-ribose) polymerase-1 (PARP-1) activity and protects pancreatic cancer cells from DNA damage," Genes Chromosomes and Cancer, vol. 50, no. 1, pp. 13-24, 2011.

[67] C. E. Ström, F. Johansson, M. Uhlén, C. A.-K. Szigyarto, K. Erixon, and T. Helleday, "Poly (ADP-ribose) polymerase (PARP) is not involved in base excision repair but PARP inhibition traps a single-strand intermediate," Nucleic Acids Research, vol. 39, no. 8, pp. 3166-3175, 2011.

[68] R. Sultana, T. Abdel-Fatah, R. Abbotts et al., "Targeting XRCC1 deficiency in breast cancer for personalized therapy," Cancer Research, vol. 73, no. 5, pp. 1621-1634, 2013.

[69] J. K. Horton, D. F. Stefanick, R. Prasad, N. R. Gassman, P. S. Kedar, and S. H. Wilson, "Base excision repair defects invoke hypersensitivity to PARP inhibition," Molecular Cancer Research, vol. 12, no. 8, pp. 1128-1139, 2014.

[70] C. J. Lord, S. McDonald, S. Swift, N. C. Turner, and A. Ashworth, "A high-throughput RNA interference screen for DNA repair determinants of PARP inhibitor sensitivity," DNA Repair, vol. 7, no. 12, pp. 2010-2019, 2008.

[71] J. Dittmer, "The role of the transcription factor Ets1 in carcinoma," Seminars in Cancer Biology, vol. 35, pp. 20-38, 2015.

[72] S. Singh, J. Barrett, K. Sakata, R. G. Tozer, and G. Singh, "ETS proteins and MMPs: partners in invasion and metastasis," Current Drug Targets, vol. 3, no. 5, pp. 359-367, 2002.

[73] J. C. Brenner and A. M. Chinnaiyan, "Translocations in epithelial cancers," Biochimica et Biophysica Acta, vol. 1796, no. 2, pp. 201-215, 2009.

[74] K. M. Baker, G. Wei, A. E. Schaffner, and M. C. Ostrowski, "Ets2 and components of mammalian SWI/SNF form a repressor complex that negatively regulates the BRCA1 promoter," The Journal of Biological Chemistry, vol. 278, no. 20, pp. 17876-17884, 2003. 
[75] V. Puzovic, I. Brcic, I. Ranogajec, and J. Jakic-Razumovic, "Prognostic values of ETS-1, MMP-2 and MMP-9 expression and co-expression in breast cancer patients," Neoplasma, vol. 61, no. 4, pp. 439-446, 2014.

[76] A. J. Legrand, S. Choul-Li, C. Spriet et al., "The level of Ets-1 protein is regulated by poly(ADP-ribose) polymerase-1 (PARP1) in cancer cells to prevent DNA damage," PLoS ONE, vol. 8, no. 2, Article ID e55883, 2013.

[77] L. Liu, W. Zhou, C.-T. Cheng et al., "TGF $\beta$ Induces 'bRCAness' and sensitivity to PARP inhibition in breast cancer by regulating DNA-repair genes," Molecular Cancer Research, vol. 12, no. 11, pp. 1597-1609, 2014.

[78] M. D. Paraskevopoulou and A. G. Hatzigeorgiou, "Analyzing MiRNA-LncRNA interactions," Methods in Molecular Biology, vol. 1402, pp. 271-286, 2016.

[79] A. Bisso, M. Faleschini, F. Zampa et al., "Oncogenic miR-181a/b affect the DNA damage response in aggressive breast cancer," Cell Cycle, vol. 12, no. 11, pp. 1679-1687, 2013.

[80] P. Moskwa, F. M. Buffa, Y. Pan et al., "MiR-182-mediated downregulation of BRCA1 Impacts DNA repair and sensitivity to PARP inhibitors," Molecular Cell, vol. 41, no. 2, pp. 210-220, 2011.

[81] S. Neijenhuis, I. Bajrami, R. Miller, C. J. Lord, and A. Ashworth, "Identification of miRNA modulators to PARP inhibitor response," DNA Repair, vol. 12, no. 6, pp. 394-402, 2013.

[82] J.-W. Huang, Y. Wang, K. K. Dhillon et al., "Systematic screen identifies miRNAs that target RAD51 and RAD51D to enhance chemosensitivity," Molecular Cancer Research, vol. 11, no. 12, pp. 1564-1573, 2013.

[83] Y. Wang, J.-W. Huang, P. Calses, C. J. Kemp, and T. Taniguchi, "MiR-96 downregulates REV1 and RAD51 to promote cellular sensitivity to cisplatin and PARP inhibition," Cancer Research, vol. 72, no. 16, pp. 4037-4046, 2012.

[84] S. Lim, A. Janzer, A. Becker et al., "Lysine-specific demethylase 1 (LSD1) is highly expressed in ER-negative breast cancers and a biomarker predicting aggressive biology," Carcinogenesis, vol. 31, no. 3, pp. 512-520, 2010.

[85] N. Serce, A. Gnatzy, S. Steiner, H. Lorenzen, J. Kirfel, and R. Buettner, "Elevated expression of LSD1 (Lysine-specific demethylase 1) during tumour progression from pre-invasive to invasive ductal carcinoma of the breast," BMC Clinical Pathology, vol. 12, article 13, 2012.

[86] N. Mosammaparast, H. Kim, B. Laurent et al., "The histone demethylase LSD1/KDM1A promotes the DNA damage response," The Journal of Cell Biology, vol. 203, no. 3, pp. 457470, 2013.

[87] S. Nagasawa, A. S. Sedukhina, Y. Nakagawa et al., "LSD1 overexpression is associated with poor prognosis in basal-like breast cancer, and sensitivity to PARP inhibition," PLoS ONE, vol. 10, no. 2, Article ID e0118002, 2015.

[88] D. Blazek, J. Kohoutek, K. Bartholomeeusen et al., “The cyclin K/Cdk12 complex maintains genomic stability via regulation of expression of DNA damage response genes," Genes \& Development, vol. 25, no. 20, pp. 2158-2172, 2011.

[89] D. Vrábel, M. Svoboda, J. Navrátil, and J. Kohoutek, "Function of CDK12 in tumor initiation and progression and its clinical consequences," Klinicka Onkologie, vol. 27, no. 5, pp. 340-346, 2014.

[90] P. M. Joshi, S. L. Sutor, C. J. Huntoon, and L. M. Karnitz, "Ovarian cancer-associated mutations disable catalytic activity of CDK12, a kinase that promotes homologous recombination repair and resistance to cisplatin and poly(ADP-ribose) polymerase inhibitors," The Journal of Biological Chemistry, vol. 289, no. 13, pp. 9247-9253, 2014.

[91] I. Bajrami, J. R. Frankum, A. Konde et al., "Genome-wide profiling of genetic synthetic lethality identifies CDK12 as a novel determinant of PARP1/2 inhibitor sensitivity," Cancer Research, vol. 74, no. 1, pp. 287-297, 2014.

[92] I. Peset and I. Vernos, "The TACC proteins: TACC-ling microtubule dynamics and centrosome function," Trends in Cell Biology, vol. 18, no. 8, pp. 379-388, 2008.

[93] P. Singh, G. E. Thomas, K. K. Gireesh, and T. K. Manna, “TACC3 protein regulates microtubule nucleation by affecting $\gamma$-tubulin ring complexes," Journal of Biological Chemistry, vol. 289, no. 46, pp. 31719-31735, 2014.

[94] B. U. Nwagbara, A. E. Faris, E. A. Bearce et al., "TACC3 is a microtubule plus end-tracking protein that promotes axon elongation and also regulates microtubule plus end dynamics in multiple embryonic cell types," Molecular Biology of the Cell, vol. 25, no. 21, pp. 3350-3362, 2014.

[95] I. H. Still, P. Vince, and J. K. Cowell, "The third member of the transforming acidic coiled coil-containing gene family, TACC3, maps in 4p16, close to translocation breakpoints in multiple myeloma, and is upregulated in various cancer cell lines," Genomics, vol. 58, no. 2, pp. 165-170, 1999.

[96] G.-H. Ha, J.-L. Kim, and E.-K. Y. Breuer, "TACC3 is essential for EGF-mediated EMT in cervical cancer," PLoS ONE, vol. 8, no. 8, article e70353, 2013.

[97] G.-H. Ha, J.-L. Kim, A. Petersson et al., “TACC3 deregulates the DNA damage response and confers sensitivity to radiation and PARP inhibition," Oncogene, 2014.

[98] T. Sourisseau, D. Maniotis, A. McCarthy et al., "Aurora-A expressing tumour cells are deficient for homology-directed DNA double strand-break repair and sensitive to PARP inhibition," EMBO Molecular Medicine, vol. 2, no. 4, pp. 130-142, 2010.

[99] M. Cazales, E. Schmitt, E. Montembault, C. Dozier, C. Prigent, and B. Ducommun, "CDC25B phosphorylation by Aurora-A occurs at the G2/M transition and is inhibited by DNA damage," Cell Cycle, vol. 4, no. 9, pp. 1233-1238, 2005.

[100] Z. Wang, Y. Liu, L. Lu et al., "Fibrillin-1, induced by Aurora-A but inhibited by BRCA2, promotes ovarian cancer metastasis," Oncotarget, vol. 6, no. 9, pp. 6670-6683, 2015.

[101] J. M. Sun, L. N. Yang, H. Xu, B. Chang, H. Y. Wang, and G. Yang, "Inhibition of Aurora A promotes chemosensitivity via inducing cell cycle arrest and apoptosis in cervical cancer cells," American Journal of Cancer Research, vol. 5, no. 3, pp. 1133-1145, 2015.

[102] J. R. Bischoff, L. Anderson, Y. Zhu et al., "A homologue of Drosophila aurora kinase is oncogenic and amplified in human colorectal cancers," EMBO Journal, vol. 17, no. 11, pp. 3052-3065, 1998.

[103] J.-L. Liu, Z. Mao, T. A. LaFortune et al., "Cell cycle-dependent nuclear export of phosphatase and tensin homologue tumor suppressor is regulated by the phosphoinositide-3-kinase signaling cascade," Cancer Research, vol. 67, no. 22, pp. 11054-11063, 2007.

[104] J. Olasz, Z. Doleschall, Z. Dunai, A. Pazsitka, and O. Csuka, "PI3K/AKT pathway activation and therapeutic consequences in breast cancer," Magyar Onkologia, vol. 59, no. 4, pp. 346-351, 2015.

[105] V. Nodouzi, M. Nowroozi, M. Hashemi, G. Javadi, and R. Mahdian, "Concurrent down-regulation of PTEN and NKX3.1 
expression in Iranian patients with prostate cancer," The International Brazilian Journal of Urology, vol. 41, no. 5, pp. 898-905, 2015.

[106] W. H. Shen, A. S. Balajee, J. Wang et al., "Essential Role for Nuclear PTEN in maintaining chromosomal integrity," Cell, vol. 128, no. 1, pp. 157-170, 2007.

[107] A. M. Mendes-Pereira, S. A. Martin, R. Brough et al., "Synthetic lethal targeting of PTEN mutant cells with PARP inhibitors," EMBO Molecular Medicine, vol. 1, no. 6-7, pp. 315-322, 2009.

[108] J.-S. Kim, C. Lee, C. L. Bonifant, H. Ressom, and T. Waldman, "Activation of p53-dependent growth suppression in human cells by mutations in PTEN or PIK3CA," Molecular and Cellular Biology, vol. 27, no. 2, pp. 662-677, 2007.

[109] J. Puc and R. Parsons, "PTEN loss inhibits CHK1 to cause double stranded-DNA breaks in cells," Cell Cycle, vol. 4, no. 7, pp. 927929, 2005.

[110] M. Fraser, H. Zhao, K. R. Luoto et al., "PTEN deletion in prostate cancer cells does not associate with loss of RAD51 function: implications for radiotherapy and chemotherapy," Clinical Cancer Research, vol. 18, no. 4, pp. 1015-1027, 2012.

[111] C. R. Hunt, A. Gupta, N. Horikoshi, and T. K. Pandita, "Does PTEN loss impair DNA double-strand break repair by homologous recombination?" Clinical Cancer Research, vol. 18, no. 4, pp. 920-922, 2012.

[112] A. A. Arbini, F. Guerra, M. Greco et al., "Mitochondrial DNA depletion sensitizes cancer cells to PARP inhibitors by translational and post-translational repression of BRCA2," Oncogenesis, vol. 2, article e82, 2013.

[113] J. A. Watkins, S. Irshad, A. Grigoriadis, and A. N. J. Tutt, "Genomic scars as biomarkers of homologous recombination deficiency and drug response in breast and ovarian cancers," Breast Cancer Research, vol. 16, no. 3, article 211, 2014.

[114] S. Rottenberg, J. E. Jaspers, A. Kersbergen et al., "High sensitivity of BRCA1-deficient mammary tumors to the PARP inhibitor AZD2281 alone and in combination with platinum drugs," Proceedings of the National Academy of Sciences of the United States of America, vol. 105, no. 44, pp. 17079-17084, 2008.

[115] T. Popova, E. Manié, G. Rieunier et al., "Ploidy and largescale genomic instability consistently identify basal-like breast carcinomas with BRCA1/2 inactivation," Cancer Research, vol. 72, no. 21, pp. 5454-5462, 2012.

[116] J. B. Geigl, A. C. Obenauf, T. Schwarzbraun, and M. R. Speicher, "Defining 'chromosomal instability", Trends in Genetics, vol. 24, no. 2, pp. 64-69, 2008.

[117] H. Farmer, H. McCabe, C. J. Lord et al., "Targeting the DNA repair defect in BRCA mutant cells as a therapeutic strategy," Nature, vol. 434, no. 7035, pp. 917-921, 2005.

[118] I. Ibragimova and P. Cairns, "Assays for hypermethylation of the BRCA1 gene promoter in Tumor cells to predict sensitivity to PARP-Inhibitor therapy," Methods in Molecular Biology, vol. 780, pp. 277-291, 2011.

[119] J. Veeck, S. Ropero, F. Setien et al., "BRCA1 CpG island hypermethylation predicts sensitivity to poly(adenosine diphosphate)-ribose polymerase inhibitors," Journal of Clinical Oncology, vol. 28, no. 29, pp. e563-e566, 2010.

[120] M. Esteller, J. M. Silva, G. Dominguez et al., "Promoter hypermethylation and BRCA1 inactivation in sporadic breast and ovarian tumors," Journal of the National Cancer Institute, vol. 92, no. 7, pp. 564-569, 2000.

[121] Y. Drew, E. A. Mulligan, W.-T. Vong et al., “Therapeutic potential of poly(ADP-ribose) polymerase inhibitor AG014699 in human cancers with mutated or methylated BRCA1 or BRCA2," Journal of the National Cancer Institute, vol. 103, no. 4, pp. 334346, 2011.

[122] A. L. Bane, A. M. Mulligan, D. Pinnaduwage, F. P. O’Malley, and I. L. Andrulis, "EMSY and CCND1 amplification in familial breast cancer: from the Ontario site of the Breast Cancer Family Registry," Breast Cancer Research and Treatment, vol. 127, no. 3, pp. 831-839, 2011.

[123] S. K. Pal and J. Mortimer, “Triple-negative breast cancer: novel therapies and new directions," Maturitas, vol. 63, no. 4, pp. 269274, 2009.

[124] N. C. Turner, C. J. Lord, E. Iorns et al., "A synthetic lethal siRNA screen identifying genes mediating sensitivity to a PARP inhibitor," The EMBO Journal, vol. 27, no. 9, pp. 1368-1377, 2008.

[125] M. W. Audeh, J. Carmichael, R. T. Penson et al., "Oral poly(ADP-ribose) polymerase inhibitor olaparib in patients with BRCA1 or BRCA2 mutations and recurrent ovarian cancer: a proof-of-concept trial," The Lancet, vol. 376, no. 9737, pp. 245251, 2010.

[126] X. Wang and D. T. Weaver, "The ups and downs of DNA repair biomarkers for PARP inhibitor therapies," American Journal of Cancer Research, vol. 1, no. 3, pp. 301-327, 2011.

[127] X. W. Meng, B. D. Koh, J.-S. Zhang et al., "Poly(ADP-ribose) polymerase inhibitors sensitize cancer cells to death receptormediated apoptosis by enhancing death receptor expression," The Journal of Biological Chemistry, vol. 289, no. 30, pp. 2054320558, 2014.

[128] M. I. Rodríguez, A. González-Flores, F. Dantzer, J. Collard, A. G. De Herreros, and F. J. Oliver, "Poly(ADP-ribose)-dependent regulation of Snaill protein stability," Oncogene, vol. 30, no. 42, pp. 4365-4372, 2011.

[129] S.-W. Yu, S. A. Andrabi, H. Wang et al., "Apoptosis-inducing factor mediates poly(ADP-ribose) (PAR) polymer-induced cell death," Proceedings of the National Academy of Sciences of the United States of America, vol. 103, no. 48, pp. 18314-18319, 2006.

[130] M. I. Rodríguez, A. Peralta-Leal, F. O’Valle et al., "PARP-1 regulates metastatic melanoma through modulation of vimentininduced malignant transformation," PLoS Genetics, vol. 9, no. 6, article e1003531, 2013.

[131] N. Chan, I. M. Pires, Z. Bencokova et al., "Contextual synthetic lethality of cancer cell kill based on the tumor microenvironment," Cancer Research, vol. 70, no. 20, pp. 8045-8054, 2010.

[132] A. Pyriochou, G. Olah, E. A. Deitch, C. Szabó, and A. Papapetropoulos, "Inhibition of angiogenesis by the poly(ADPribose) polymerase inhibitor PJ-34," International Journal of Molecular Medicine, vol. 22, no. 1, pp. 113-118, 2008.

[133] L. Tentori, P. M. Lacal, A. Muzi et al., "Poly(ADP-ribose) polymerase (PARP) inhibition or PARP-1 gene deletion reduces angiogenesis," European Journal of Cancer, vol. 43, no. 14, pp. 2124-2133, 2007.

[134] M. Rajesh, P. Mukhopadhyay, S. Bátkai et al., "Pharmacological inhibition of poly(ADP-ribose) polymerase inhibits angiogenesis," Biochemical and Biophysical Research Communications, vol. 350, no. 2, pp. 352-357, 2006.

[135] N. Chan, M. Koritzinsky, H. Zhao et al., "Chronic hypoxia decreases synthesis of homologous recombination proteins to offset chemoresistance and radioresistance," Cancer Research, vol. 68, no. 2, pp. 605-614, 2008.

[136] V. M. Neumeister, C. A. Sullivan, R. Lindner et al., "Hypoxiainduced protein CAIX is associated with somatic loss of BRCA1 protein and pathway activity in triple negative breast cancer," 
Breast Cancer Research and Treatment, vol. 136, no. 1, pp. 67-75, 2012.

[137] K. R. Luoto, R. Kumareswaran, and R. G. Bristow, "Tumor hypoxia as a driving force in genetic instability," Genome Integrity, vol. 4, article 5, 2013.

[138] S. J. Hill, A. P. Clark, D. P. Silver, and D. M. Livingston, "BRCA1 pathway function in basal-like breast cancer cells," Molecular and Cellular Biology, vol. 34, no. 20, pp. 3828-3842, 2014.

[139] G. Illuzzi, E. Fouquerel, J.-C. Amé et al., "PARG is dispensable for recovery from transient replicative stress but required to prevent detrimental accumulation of poly(ADP-ribose) upon prolonged replicative stress," Nucleic Acids Research, vol. 42, no. 12, pp. 7776-7792, 2014.

[140] J. Luo, N. L. Solimini, and S. J. Elledge, "Principles of cancer therapy: oncogene and non-oncogene addiction," Cell, vol. 136, no. 5, pp. 823-837, 2009.

[141] J. M. Stommel, A. C. Kimmelman, H. Ying et al., "Coactivation of receptor tyrosine kinases affects the response of tumor cells to targeted therapies," Science, vol. 318, no. 5848, pp. 287-290, 2007.

[142] V. Schreiber, F. Dantzer, J.-C. Amé, and G. de Murcia, "Poly(ADP-ribose): novel functions for an old molecule," Nature Reviews Molecular Cell Biology, vol. 7, no. 7, pp. 517-528, 2006.

[143] C. E. Redon, A. J. Nakamura, Y.-W. Zhang et al., "Histone $\gamma \mathrm{H} 2 \mathrm{AX}$ and poly(ADP-ribose) as clinical pharmacodynamic biomarkers," Clinical Cancer Research, vol. 16, no. 18, pp. 45324542, 2010.

[144] P. Gottipati, B. Vischioni, N. Schultz et al., "Poly(ADP-ribose) polymerase is hyperactivated in homologous recombinationdefective cells," Cancer Research, vol. 70, no. 13, pp. 5389-5398, 2010.

[145] L. Liu, W. Zhou, C.-T. Cheng et al., "TGF $\beta$ Induces 'bRCAness' and Sensitivity to PARP inhibition in breast cancer by regulating DNA-repair genes," Molecular Cancer Research, vol. 12, no. 11, pp. 1597-1609, 2014.

[146] Y. Wang, Y. Yu, A. Tsuyada et al., "Transforming growth factor$B$ regulates the sphere-initiating stem cell-like feature in breast cancer through miRNA-181 and ATM,' Oncogene, vol. 30, no. 12, pp. 1470-1480, 2011.

[147] L. Hughes-Davies, D. Huntsman, M. Ruas et al., "EMSY links the BRCA2 pathway to sporadic breast and ovarian cancer," Cell, vol. 115, no. 5, pp. 523-535, 2003.

[148] I. Cousineau and A. Belmaaza, "EMSY overexpression disrupts the BRCA2/RAD51 pathway in the DNA-damage response: implications for chromosomal instability/recombination syndromes as checkpoint diseases," Molecular Genetics and Genomics, vol. 285, no. 4, pp. 325-340, 2011.

[149] P. M. Wilkerson, K. J. Dedes, D. Wetterskog et al., "Functional characterization of EMSY gene amplification in human cancers," The Journal of Pathology, vol. 225, no. 1, pp. 29-42, 2011.

[150] S. M. Domchek, C. Aghajanian, R. Shapira-Frommer et al., "Efficacy and safety of olaparib monotherapy in germline BRCA1/2 mutation carriers with advanced ovarian cancer and three or more lines of prior therapy," Gynecologic Oncology, vol. 140, no. 2, pp. 199-203, 2016.

[151] J. Ledermann, P. Harter, C. Gourley et al., "Olaparib maintenance therapy in patients with platinum-sensitive relapsed serous ovarian cancer: a preplanned retrospective analysis of outcomes by BRCA status in a randomised phase 2 trial," The Lancet Oncology, vol. 15, no. 8, pp. 852-861, 2014.
[152] BMN 673 (Talazoparib), an Oral PARP Inhibitor, in People with Deleterious BRCA1/2 Mutation-Associated Ovarian Cancer Who Have Had Prior PARP Inhibitor Treatment, May 2016, https://clinicaltrials.gov/ct2/show/NCT02326844?term=talazoparib\&rank=9.

[153] A Study Evaluating Talazoparib (BMN 673), a PARP Inhibitor, in Advanced and/or Metastatic Breast Cancer Patients with BRCA Mutation (EMBRACA Study), (EMBRACA), May 2016, https:/clinicaltrials.gov/ct2/show/NCT01945775?term=talazoparib\&rank=8.

[154] Veliparib, Bendamustine Hydrochloride, and Rituximab in Treating Patients with Relapsed or Refractory Lymphoma, Multiple Myeloma, or Solid Tumors, October 2015, https:// clinicaltrials.gov/ct2/show/NCT01326702?term=veliparib\& rank=10.

[155] Veliparib and Topotecan for Relapsed Ovarian Cancer with Negative or Unknown BRCA Status, June 2015, https://clinicaltrials.gov/ct2/show/NCT01690598?term=veliparib\&rank=22.

[156] Gemcitabine Hydrochloride and Cisplatin with or Without Veliparib or Veliparib Alone in Treating Patients with Locally Advanced or Metastatic Pancreatic Cancer, June 2016, https:// clinicaltrials.gov/ct2/show/NCT01585805?term=nct01585805\& rank=1.

[157] A Study of Rucaparib in Patients with Pancreatic Cancer and a Known Deleterious BRCA Mutation, December 2015, https://clinicaltrials.gov/ct2/show/NCT02042378?term=rucaparib\&rank=1.

[158] A Study of Rucaparib as Switch Maintenance Following Platinum-Based Chemotherapy in Patients with PlatinumSensitive, High-Grade Serous or Endometrioid Epithelial Ovarian, Primary Peritoneal or Fallopian Tube Cancer (ARIEL3), April 2016, https://clinicaltrials.gov/ct2/show/NCT01968213? term $=$ rucaparib\&rank $=3$.

[159] ESP1/SARC025 Global Collaboration: A Phase I Study of a Combination of the PARP Inhibitor, Niraparib and Temozolomide or Irinotecan in Patients with Previously Treated, Incurable Ewing Sarcoma, May 2016, https://clinicaltrials .gov/ct2/show/NCT02044120?term=niraparib\&rank=7.

[160] "A phase III trial of niraparib versus physician's choice in HER2 negative, germline BRCA mutation-positive breast cancer patients (BRAVO)," https://clinicaltrials.gov/ct2/show/ NCT01905592?term=niraparib\&rank=6.

[161] A Study of Niraparib in Patients with Ovarian Cancer Who Have Received at Least Three Previous Chemotherapy Regimens, January 2016, https://clinicaltrials.gov/ct2/show/ NCT02354586?term=niraparib\&rank=5. 


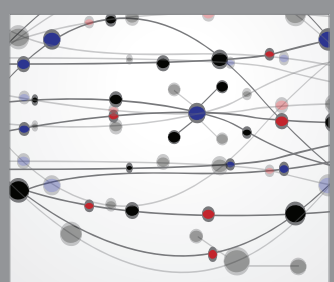

The Scientific World Journal
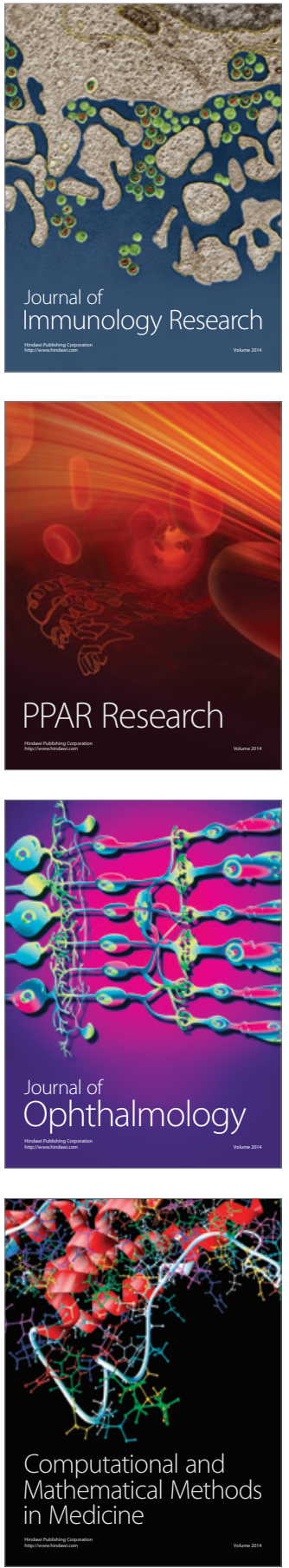

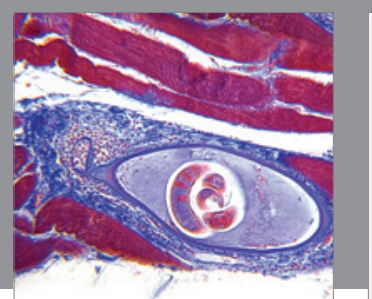

Gastroenterology Research and Practice

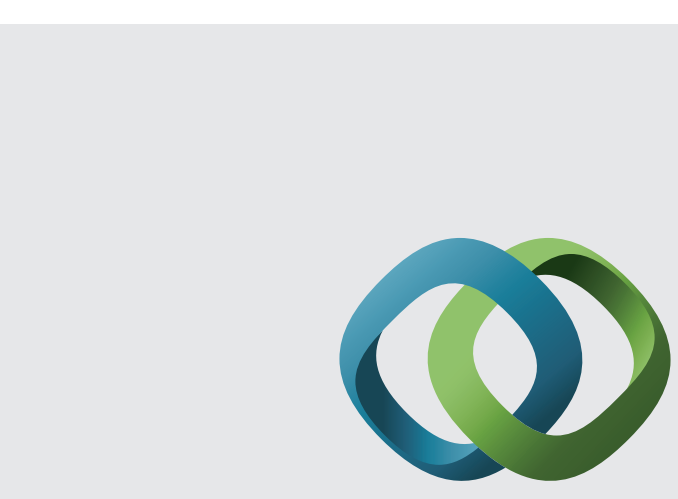

\section{Hindawi}

Submit your manuscripts at

http://www.hindawi.com
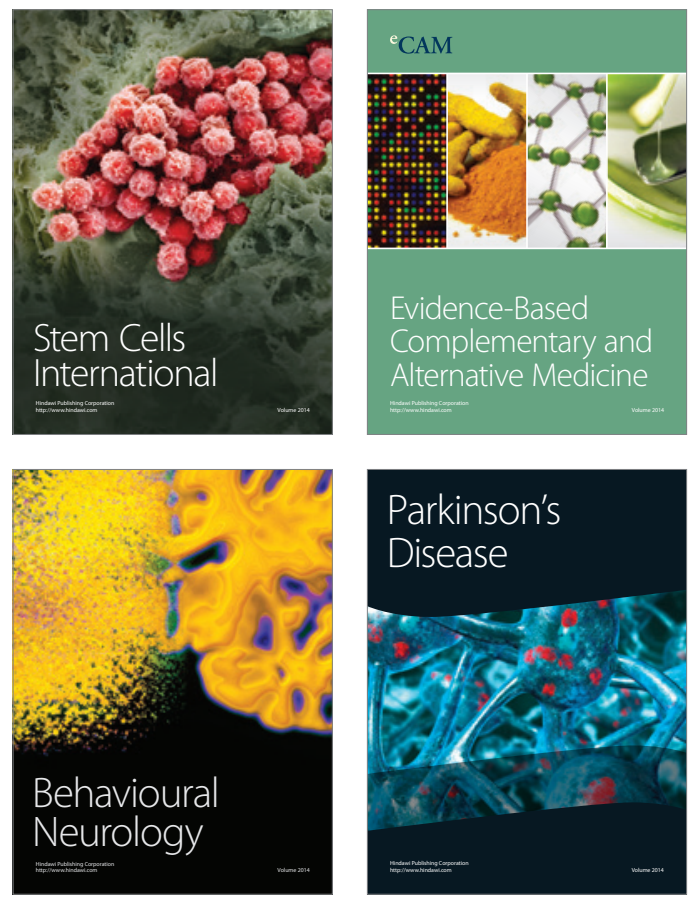
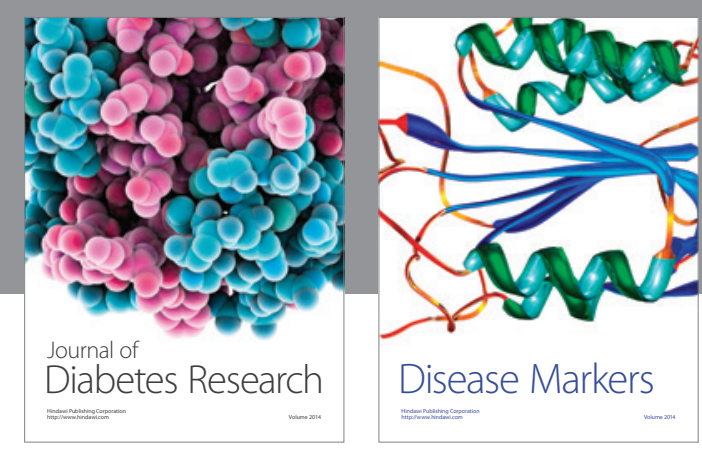

Disease Markers
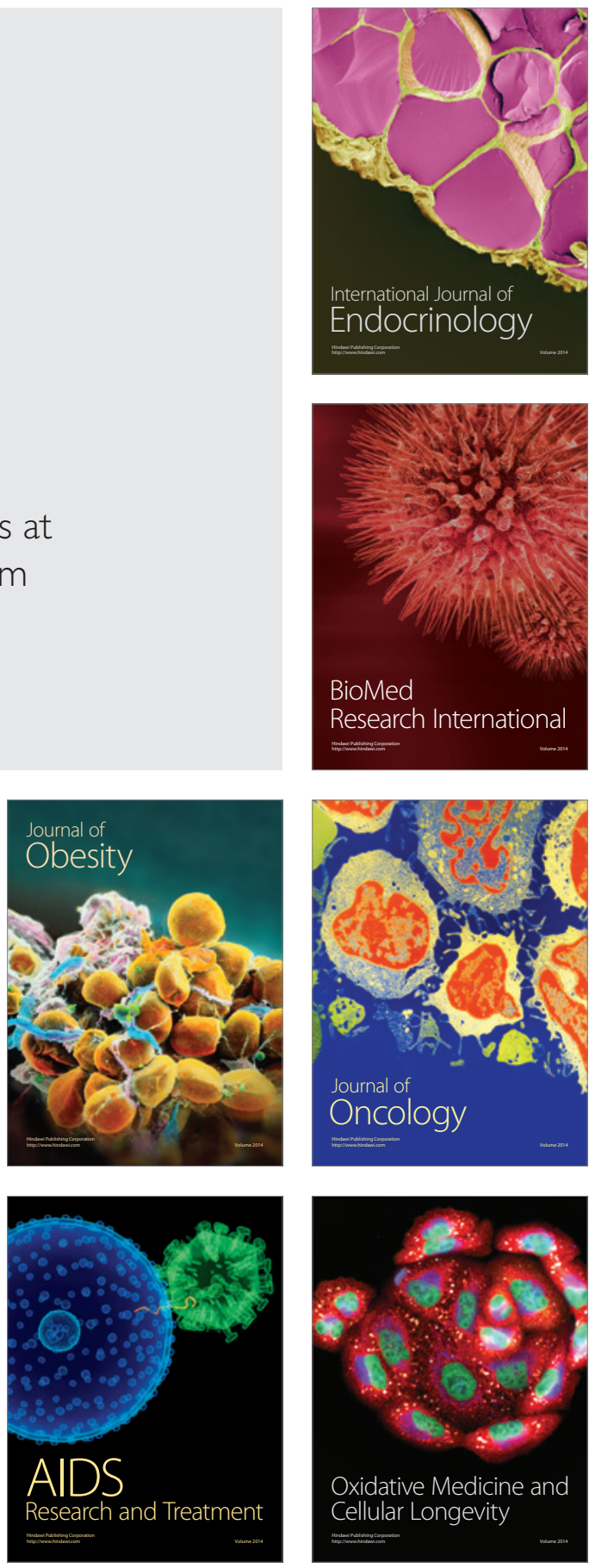